\title{
BMJ Open Socioeconomically disadvantaged smokers' ratings of plain and branded cigarette packaging: an experimental study
}

\author{
Ashleigh Guillaumier, ${ }^{1}$ Billie Bonevski, ${ }^{1}$ Chris Paul, ${ }^{2}$ Sarah Durkin, ${ }^{3}$ \\ Catherine D'Este ${ }^{4}$
}

To cite: Guillaumier $A$, Bonevski B, Paul C, et al. Socioeconomically disadvantaged smokers ratings of plain and branded cigarette packaging: an experimental study. BMJ Open 2014;4:e004078. doi:10.1136/ bmjopen-2013-004078

- Prepublication history for this paper is available online To view these files please visit the journal online (http://dx.doi.org/10.1136/ bmjopen-2013-004078)

Received 20 September 2013 Accepted 10 January 2014

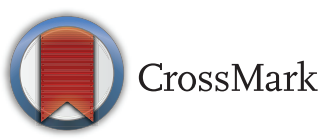

For numbered affiliations see end of article.

Correspondence to Ashleigh Guillaumier; Ashleigh.Guillaumier@ newcastle.edu.au

\section{ABSTRACT}

Objectives: This study aimed to test the potential impact of plain packaging for cigarettes on brand appeal among highly socioeconomically disadvantaged smokers using the new design for cigarettes implemented in Australia, which combines plain packaging with larger health warning labels.

Design: A 2×2 factorial design trial embedded within a cross-sectional computer touchscreen survey. Data were collected between March and December 2012.

Setting: Socially disadvantaged welfare aid recipients were recruited through a large Social and Community Service Organisation in New South Wales, Australia.

Participants: $\mathrm{N}=354$ smokers. The majority of the sample had not completed high school (64\%), earned less than $\$ A 300 /$ week (55\%) and received their income from Government payments (95\%).

Interventions: Participants were randomised to one of the four different pack conditions determined by brand name: Winfield versus Benson \& Hedges, and packaging type: branded versus plain. Participants were required to rate their assigned pack on measures of brand appeal and purchase intentions.

Results: Plain packaging was associated with significantly reduced smoker ratings of 'positive pack characteristics' $(p<0.001)$, 'positive smoker characteristics' $(p=0.003)$ and 'positive taste characteristics' $(p=0.033)$ in the Winfield brand name condition only. Across the four pack conditions, no main differences were found for 'negative smoker characteristics' $(p=0.427)$ or 'negative harm characteristics' $(p=0.411)$. In comparison to plain packaging, the presentation of branded packaging was associated with higher odds of smokers' purchase intentions ( $\mathrm{OR}=2.18,95 \% \mathrm{Cl} 1.34$ to $3.54 ; \mathrm{p}=0.002)$.

Conclusions: Plain packs stripped of branding elements, featuring larger health warning labels, were associated with reduced positive cigarette brand image and purchase intentions among highly socioeconomically disadvantaged smokers.

\section{INTRODUCTION}

Smoking rates are disproportionately high among groups who experience multiple
Strengths and limitations of this study

- This study is the first to obtain a large sample of socially disadvantaged smokers' responses to a simulation of a one-off exposure to an important tobacco control policy development.

- Use of a convenience sample limits the external validity and generalisability of the results.

- Use of a wider range of brands for comparison is recommended for research in countries considering implementing plain packaging.

levels of disadvantage such as those with low income $(26 \%),{ }^{1}$ indigenous populations $(50 \%),{ }^{2}$ the homeless $(69-73 \%)^{3} 4$ and individuals with a mental illness $(35-90 \%) .^{5-7}$ Comparatively, the population smoking rate in Australia is 15\%. ${ }^{1}$ Therefore, evaluating tobacco control approaches for effectiveness with disadvantaged social groups is a priority.

Cigarette manufacturers use the cigarette pack to promote their product in a number of ways. The cigarette pack is highly visible to the user and others, ${ }^{8}$ and reinforces brand image. ${ }^{9}$ Packaging distinguishes brands from competitors and communicates brand imagery, character and values. ${ }^{9} 10$ Pack design can also be used to target segments of the market. For example, packs targeting women typically use bright graphics and feminine colours, descriptor terms such as 'slim' and 'thin' and packaging with increased height and decreased width compared with standard packaging. ${ }^{11}$ To engage the youth market, pack designs are novel, with fashionable designs and attractive imagery, have innovative pack construction (ie, pack shape and method of opening) and promote 'mild' taste or 'smoothness'. ${ }^{2}$ Economy packs that emphasise quality are important for targeting low-income smokers, and often use design elements such as printing product price on packaging. ${ }^{13}$ Packaging has been particularly important in markets such as 
Australia where stringent advertising restrictions have long prohibited traditional avenues of advertising and promotion of brand and product.

Design elements of the cigarette pack are constructed to capture starter smokers, encourage brand-switching and brand loyalty and to expand market share. ${ }^{9} 13$ Packaging colours, product descriptors, brand imagery and logos have all been shown to impact on the perceptions and experiences of the product. ${ }^{14}$ A colour code for tobacco products is well established: lighter packaging colours are perceived to contain a product that is less harmful to health. Numerous studies have shown that smokers associate the colour 'red' with high strength and harshness, 'blue' as being mild and anything progressively lighter as healthier or less harmful. ${ }^{15} 16$ Similarly, many countries have banned the use of descriptor terms such as 'light', 'mild' and 'low tar' as cigarettes labelled with these terms are falsely perceived as being less harmful to health, and easier to give up. ${ }^{16}$ Replacement terms such as 'gold', 'silver' and 'smooth' were still perceived as less harmful than regular varieties, suggesting that removal of both colours and descriptor terms may be more effective than the removal of either alone in reducing false beliefs about tobacco risk. ${ }^{14}$ Health warning labels (HWLs) that use pictures, supportive text and take up larger portions of the pack space have been shown to increase the effectiveness of the warnings in communicating risk and promoting cessation. ${ }^{17} 18$ Specifically, in a cross-sectional survey in the USA, Bansal-Travers et $a l^{17}$ found that participants selected larger, pictorial and lossframed HWLs as the most effective in communicating health risks.

Evidence from plain packaging simulation studies shows that progressively plainer cigarette packaging, incorporating larger HWLs and fewer branding elements, was perceived as less attractive, ${ }^{19}{ }^{20}$ reduced false beliefs about tobacco risk ${ }^{14} 17$ and was associated with cessation intentions. ${ }^{80}$ Wakefield and colleagues have conducted a number of online simulation experiments, exposing participants to pack conditions which vary by brand, degree of plain packaging ${ }^{19}{ }^{21}$ and HWL size. ${ }^{20}$ The studies found that packs with progressively fewer branding elements were perceived as less appealing overall, ${ }^{19}$ larger HWLs combined with plain packs reduced adolescents' positive ratings of packs, ${ }^{21}$ and presentation of plain packs compared with branded packs increased participant intentions of not purchasing a pack. ${ }^{20}$ However, none of these studies examined differences in effects by socioeconomic status (SES). Additionally, best-worst ${ }^{8}$ and experimental auction $^{22}$ studies have found plain packs featuring large graphic HWLs were the most effective pack type in reducing demand and promoting cessation among adult smokers.

The Australian Government's Tobacco Plain Packaging Act 2011 legislated mandatory plain and standardised packaging on cigarettes sold in Australia, which include dark colour, pictorial and supportive text HWLs that cover at least 75\% front-of-pack and 90\% back-of-pack, have all logos and branding removed and use only specified font styles and sizes. ${ }^{23}$ The policy also limits pack and stick dimensions. The legislation was introduced to reduce product appeal, increase the effectiveness of health warnings and reduce misperceptions about the harms of smoking. The first study to examine effects of plain packaging during the roll-out phase using a computer-assisted telephone survey found that compared with smokers smoking from branded packs, smokers with plain packs were more likely to perceive their tobacco as being lower in quality and satisfaction, to think about and prioritise quitting and to support the plain packaging policy. ${ }^{24}$ However, this study had a low representation of disadvantaged smokers, did not examine effects by SES and did not control for novelty of HWL content. While there is evidence of reduced appeal for plain packaging compared with branded packaging of tobacco products within the general population, it is important to investigate whether similar effects are likely to occur for groups experiencing social and financial hardship. The aim of this study was to examine brand appeal and purchase intentions associated with branded cigarette packs compared with the new design, Australian plain packs, among a sample of socioeconomically disadvantaged smokers.

\section{METHODS \\ Design}

A two-by-two packaging type (branded vs plain) by brand name (Winfield vs Benson \& Hedges $(\mathrm{B} \& \mathrm{H})$ ) factorial experimental design was used, thereby randomly exposing participants to one of a possible four cigarette pack conditions. Each participant completed a uniform series of pack ratings within the experimental condition they were assigned. Data were collected using a touchscreen computer between March and December 2012.

\section{Setting and sample}

As the target population for the study was smokers with high social disadvantage, the sample was drawn from a service outlet of a large, national non-government, social and community service organisation (SCSO). The service provides 'emergency relief' welfare such as food vouchers, grocery items and financial aid to individuals experiencing various forms of social and financial hardship in a large catchment area of Western Sydney, New South Wales. The client profile of SCSO's includes an over-representation of disadvantaged groups including Aboriginal and Torres Strait Islanders, single parents, long-term unemployed and those whose primary income is a government benefit. ${ }^{25}$

Those eligible to participate were clients aged over 18 years, able to comprehend English and who were not too ill or distressed to take part (as judged by SCSO staff). Previous research has demonstrated high smoking prevalence rates of $60-70 \%$ among SCSO clients. ${ }^{26}$ 


\section{Recruitment}

Clients were introduced to the study when they attended the SCSO for their emergency relief appointment. SCSO staff explained that a touchscreen computer survey about smoking was being conducted, and if clients were interested, they were led to a private room where a research assistant (RA) provided further detailed information. The RA provided assistance to complete the survey if required. As the survey was anonymous, survey completion was taken as implied consent. Participants were reimbursed for their time with an $\$ A 20$ grocery voucher.

\section{Smoking status}

Smoking status was assessed by asking 'Do you currently smoke tobacco products?' with response options (1) 'yes, daily', (2) 'yes, at least once a week', (3) 'yes, but less often than once a week' and (iv) 'No, not at all', followed by asking 'Have you smoked at least 100 cigarettes or a similar amount of tobacco in your life' (yes/no/not sure). Those who reported to smoke daily, or who reported to smoke occasionally as well as having smoked at least 100 cigarettes in their life were classified as current smokers. Once smoking status was assessed, nonsmokers exited from the survey.

\section{Presentation of experimental conditions}

The study was conducted on a Dell Latitude XT3 (2.50 GHz processor) touchscreen computer, using Digivey V.4 software. ${ }^{27}$ Participants were randomly allocated to one of the four cigarette pack conditions by Digivey's randomise function, which uses a pseudo random number generator provided by the underlying programming language (see: http://msdn.microsoft.com/en-us/library/system. random( $(\mathrm{v}=\mathrm{vs} .90)$. aspx $)$. Branded pack conditions replicated cigarette packs available for purchase at the time of survey; plain pack conditions tested the new plain packaging design, combining plain packaging stripped of branding elements with larger HWLs. The four pack conditions were: (1) branded Winfield Blue 25; (2) plain Winfield Blue 25; (3) branded B\&H Smooth 25 and (4) plain B\&H Smooth 25 (see figure 1). Within each pack condition, respondents were presented with a standard set of items to rate their assigned pack. All pack conditions featured the same graphic image and text HWL: 'smoking causes peripheral vascular disease' that first appeared on Australian cigarette packs in 2006. The brands used were two of the most popular brand variants in the Australian mainstream (Winfield (Blue 25)) and premium (B\&H (Smooth 25)) cigarette markets. ${ }^{28}$ Plain pack digital images were created using specifications outlined in the Australian Government's Tobacco Plain Packaging Act 2011, while images of branded packs were supplied by the Centre for Behavioural Research in Cancer, Victoria, Australia.

\section{Outcome measures}

Brand appeal

While viewing the assigned pack image, respondents were asked to rate packs on various pack, smoker and taste characteristic statements (see table 1). These items were developed by Wakefield et $a l^{19-21}$ based on past tobacco industry packaging studies used to assess pack attractiveness, brand imagery characteristics and perceived sensory attributes. Among adult smokers, these items have variably been used as: individual outcome items ${ }^{19}$; or combined to form four outcome scales and one individual item with inter-item reliability statistics presented. ${ }^{20}$

Brand appeal rating items were combined to form four scales and one stand-alone item in order to replicate the outcome measure structure of Wakefield $e t$ als previous plain packaging study. ${ }^{20}$ The outcome measures

Table 1 Standard items used to assess responses to pack images

\begin{tabular}{ll}
\hline Survey items & Response scale \\
\hline Pack characteristics: How well do you think the following phrases relate to the cigarette & $\begin{array}{l}\text { Response scale: } 1 \text { (not at all) to } 7 \\
\text { (extremely) }\end{array}$ \\
pack shown? & \\
This pack is popular among smokers & Response scale: 1 (not at all) to 7 \\
This pack is attractive & (extremely) \\
This pack is sophisticated & \\
Smoker characteristics: How well do you think the following characteristics describe a & Response scale: 1 (not at all) to 7 \\
typical smoker of the pack shown? & (extremely) \\
A typical smoker of this pack is trendy & \\
A typical smoker of this pack is boring & \\
A typical smoker of this pack is successful & \\
Taste attributes: Please rate the following phrases describing the taste of cigarettes from & \\
the pack shown. & \\
I would expect the cigarettes in this pack to be enjoyable to smoke & \\
I would expect the cigarettes in this pack to be high in tar and nicotine & \\
I would expect the cigarettes in this pack to be satisfying in taste & \\
I would expect the cigarettes in this pack to be harmful to your health &
\end{tabular}


were: (1) positive pack characteristics-'popular among smokers'; 'attractive'; 'sophisticated'; 'a brand you might try/smoke'; (2) positive smoker characteristics-'trendy' and 'successful'; (3) negative smoker characteristic —'boring'; (4) positive taste characteristics-'enjoyable to smoke' and 'satisfying in taste' and (5) negative harm characteristics-'high in tar and nicotine' and 'harmful to your health'. Although these measures have shown strong-to-moderate internal consistency on Cronbach's $\alpha$ previously, ${ }^{20}$ they have not been tested in the current population, thus we undertook Cronbach's $\alpha$ assessment on scales with more than one item.

Scale reliability assessments revealed that the outcome measures had a moderate-to-strong internal consistency: positive pack characteristics $(\alpha=0.83)$; positive smoker characteristics $(\alpha=0.71)$; positive taste $(\alpha=0.84)$, and negative harm characteristics $(\alpha=0.65)$.

\section{Purchase intentions}

Participants were presented with images of the two brand name options (Winfield and $\mathrm{B} \& \mathrm{H}$ ) on a single screen and asked: "If you ran out of cigarettes and only the packs below were available in the store you went to, which would you be most tempted to buy?" Participants could choose between the two brand name images or select 'I would not buy any'. Participants who had previously viewed and rated a plain packaging image (ie, pack B or D; see figure 1) received plain image response options, and those who had previously rated a branded packaging image (ie, pack A or $\mathrm{C}$ ) received branded image response options at this question.

\section{Sociodemographic variables}

Gender, age, income, income source, Aboriginal or Torres Strait Islander status, marital status, highest level of education and housing type were assessed.

\section{Statistical analyses}

Analyses were conducted using Stata V.11 (http://www. stata.com). Characteristics of participants are presented by intervention group to assess the success of the randomisation.

\section{Outcome measure assessment}

As the outcome variables were not normally distributed, we used non-parametric methods for analysis. Median scores with $95 \%$ CIs are presented graphically for each of the four pack conditions. Exploratory data analysis indicated that there may be a potential pack type by brand name interaction, that is, the relationship between packaging types (branded vs plain packaging) differed for the two different cigarette brand names. As the study had limited statistical power to assess interaction effects, we did not formally test this, but undertook analysis considering the four pack conditions separately, rather than as a factorial design. The Kruskal-Wallis test was used as a global assessment of differences in factor scores among the four pack conditions. If the $p$ value for this test was
$<0.1$, pairwise comparisons using the Wilcoxon rank sum test were undertaken to compare median scores between branded packaging and plain packaging for each of the two brand names. OR analyses were used to assess the effect of packaging type (branded vs plain) on purchase intention.

Sample size for this study was determined by requirements for another trial for which participants were recruited. Post hoc power calculations demonstrated that a sample of 350 participants (approximately 85 in each of the pack type by brand name groups) would allow detection of differences in scores between branded and plain packaging (within each brand name) of approximately half an SD, with 5\% significance level and 90\% power (to allow for some loss of power due to the use of non-parametric analyses).

\section{RESULTS}

\section{Sample}

A total of 787 clients were approached by SCSO staff during the study period and 608 were eligible to be approached to participate by the RA. Of those, 581 (96\%) completed the survey and $362(62 \%)$ of them were identified as current smokers (daily and occasional). Eight smokers were excluded as they primarily used something other than manufactured or roll-your-own tobacco. The demographic details of the study participants in each intervention group are presented in table 2. The majority of the sample had not finished high school (64\%), earned less than \$A300/week $(55 \%)$ and received their income from Government benefit payments $(95 \%)$. Sociodemographic characteristics were similar across the four intervention groups.

\section{Brand appeal ratings}

Figure 2 displays ratings across the four pack conditions on the positive pack (A), positive smoker (B), negative smoker (C), positive taste (D) and negative harm (E) response scales. The positive pack scale varied significantly across the pack conditions $(p=0.001)$, with pairwise comparisons revealing that branded packaging images were rated significantly more positively than plain packaging images in the Winfield condition $(p<0.001)$; however, there was no difference in the $\mathrm{B} \& \mathrm{H}$ condition ( $p=0.102$; see table 3 ). Positive smoker characteristic ratings were significantly different across the four pack conditions $(\mathrm{p}=0.003)$; branded packaging images were rated more positively than plain packaging images within the Winfield condition $(p=0.001)$, but not the $\mathrm{B} \& \mathrm{H}$ brand name condition ( $\mathrm{p}=0.197$; see table 3$)$. There was no difference in the negative smoker characteristic ratings across the four pack conditions $(p=0.427)$. The four pack conditions were rated significantly differently when assessing positive taste characteristics $(p=0.033)$. Pairwise comparisons revealed that plain packaging images were less appealing on taste attributes than branded packaging images for the Winfield 
Table 2 Demographic characteristics of the survey sample $(\mathrm{N}=354)$

\begin{tabular}{|c|c|c|c|c|c|}
\hline Characteristic & $\begin{array}{l}\text { Winfield branded } \\
\text { N (\%) }\end{array}$ & $\begin{array}{l}\text { Winfield plain } \\
\mathbf{N}(\%)\end{array}$ & $\begin{array}{l}\text { B\&H branded } \\
\text { N (\%) }\end{array}$ & $\begin{array}{l}\text { B\&H plain } \\
\text { N (\%) }\end{array}$ & $\begin{array}{l}\text { Total } \\
\text { N (\%) }\end{array}$ \\
\hline $\mathrm{N}$ & $92(26)$ & $95(27)$ & $88(25)$ & $79(22)$ & 354 \\
\hline \multicolumn{6}{|l|}{ Age } \\
\hline 18-39 & $56(61)$ & $51(54)$ & $51(58)$ & $48(61)$ & $206(58)$ \\
\hline $40+$ & 36 (39) & $44(46)$ & $37(42)$ & $31(39)$ & $148(42)$ \\
\hline \multicolumn{6}{|l|}{ Gender } \\
\hline Female & $61(66)$ & $46(52)$ & $66(70)$ & $43(54)$ & $216(61)$ \\
\hline \multicolumn{6}{|l|}{ Aboriginal and/or Torres Strait Islander } \\
\hline Yes & $23(25)$ & $14(16)$ & $17(18)$ & $10(13)$ & $64(18)$ \\
\hline \multicolumn{6}{|l|}{ Marital status } \\
\hline Married/de facto/living with partner & $29(32)$ & $15(17)$ & $23(24)$ & $20(25)$ & $87(25)$ \\
\hline Separated/divorced & $27(29)$ & $29(33)$ & $27(28)$ & $20(25)$ & $103(29)$ \\
\hline Never married/single/widowed & $36(39)$ & $44(50)$ & $45(47)$ & 39 (49) & $164(46)$ \\
\hline \multicolumn{6}{|l|}{ Highest education } \\
\hline Primary school & $0(0)$ & $4(5)$ & $4(4)$ & $4(5)$ & $12(3.4)$ \\
\hline High school $7-10$ years & $62(67)$ & $54(61)$ & $59(62)$ & $39(49)$ & $214(61)$ \\
\hline High school $11-12$ years & $11(12)$ & $13(15)$ & $13(14)$ & $14(18)$ & $51(14)$ \\
\hline TAFE/trade qualification & $14(16)$ & $13(15)$ & $16(17)$ & $21(27)$ & $64(18)$ \\
\hline University degree & $5(5)$ & $4(5)$ & $3(3)$ & $1(1)$ & $13(3.7)$ \\
\hline \multicolumn{6}{|l|}{ Personal weekly income } \\
\hline$<\$ A 299$ & $54(59)$ & $55(58)$ & $48(56)$ & $38(48)$ & $195(55)$ \\
\hline$>\$ A 300$ & $36(39)$ & $33(35)$ & $31(35)$ & $37(47)$ & 137 (39) \\
\hline Prefer not to answer & $2(2)$ & $7(7)$ & $9(10)$ & $4(5)$ & $22(6)$ \\
\hline \multicolumn{6}{|l|}{ Income source } \\
\hline Paid work & $6(7)$ & $2(2)$ & $4(4)$ & $1(1)$ & $13(3.7)$ \\
\hline Government payment (Centrelink) & $85(92)$ & $85(97)$ & $89(94)$ & $76(96)$ & $335(95)$ \\
\hline Other & $1(1)$ & $1(1)$ & $2(2)$ & $2(3)$ & $6(1.7)$ \\
\hline \multicolumn{6}{|l|}{ Housing type } \\
\hline Own house/private rental & $26(28)$ & $31(33)$ & $28(32)$ & $23(29)$ & $108(31)$ \\
\hline Government rental & $55(60)$ & $42(44)$ & $44(50)$ & $43(54)$ & $184(52)$ \\
\hline Homeless/supported accommodation & $11(12)$ & $22(23)$ & $16(18)$ & $13(17)$ & $62(18)$ \\
\hline \multicolumn{6}{|l|}{ Regular cigarette brand } \\
\hline Winfield & $10(17)$ & $16(21)$ & $14(24)$ & $10(18)$ & $50(20)$ \\
\hline$B \& G$ & $1(1.7)$ & $1(1.3)$ & 2 (3.5) & $0(0)$ & $4(1.6)$ \\
\hline Other & $36(62)$ & $50(65)$ & $34(59)$ & $36(66)$ & $156(63)$ \\
\hline I do not have a regular brand & $11(19)$ & $10(13)$ & $8(14)$ & 9 (16) & $38(15)$ \\
\hline \multicolumn{6}{|l|}{ Regular tobacco type } \\
\hline Manufactured cigarettes & $58(63)$ & $77(81)$ & $58(66)$ & $55(70)$ & $248(70)$ \\
\hline Roll-your-own tobacco & $34(37)$ & 18 (19) & $30(34)$ & $24(30)$ & $106(30)$ \\
\hline
\end{tabular}

condition ( $p=0.004)$; however, there were no differences detected in taste ratings between plain and branded packaging images in the $\mathrm{B} \& \mathrm{H}$ condition. The four pack conditions rated similarly with regard to negative harm characteristics $(p=0.411)$ as shown in figure $2 \mathrm{E}$ and table 3 .

\section{Purchase intent}

Participants were asked to choose which pack, if any, they would prefer to purchase out of the two brand names used in this study. Participants who viewed plain packaging images only were more likely to select that they would not buy any of the presented options $(35 \%)$, compared with those who viewed branded packaging images $(19 \%$; OR=2.2, $95 \%$ CI 1.3 to 3.5 ; $\mathrm{p}=0.002)$.

\section{DISCUSSION}

This study found that plain cigarette packs were rated as significantly less appealing than branded packs in a sample of socioeconomically disadvantaged smokers. Branded packaging was viewed as more appealing, smokers of these packs were rated in a more positive way and the cigarette taste was preferred compared to cigarettes in plain packaging. No differences between branded and plain packaging relating to negative smoker or negative harm characteristics were detected. Finally, plain packaging reduced cigarette purchase intentions in comparison with branded packaging among smokers. The overall results of this study are supportive of previous plain packaging simulation research conducted with general population samples, suggesting that plain packs are viewed less favourably on measures of brand appeal than branded packs. $^{19} 20$ 


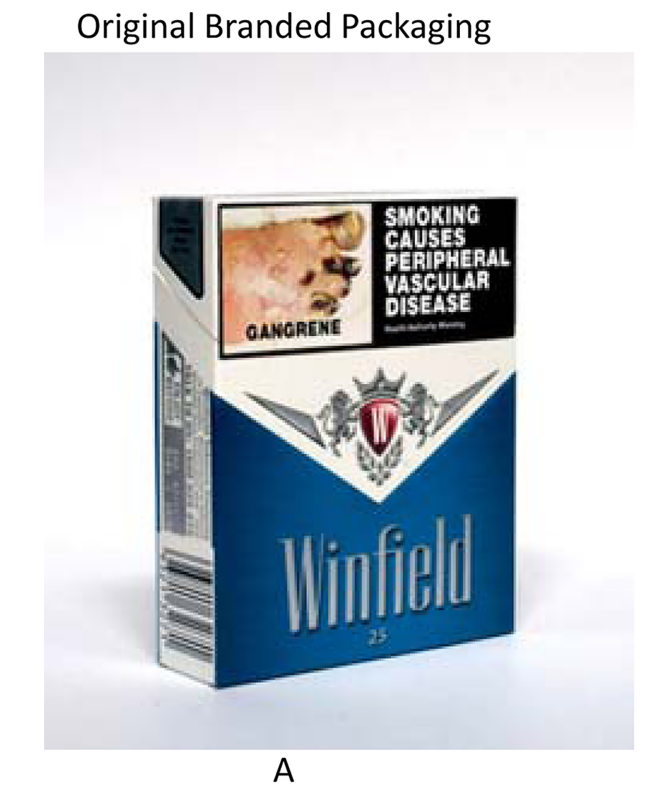

Plain Packaging
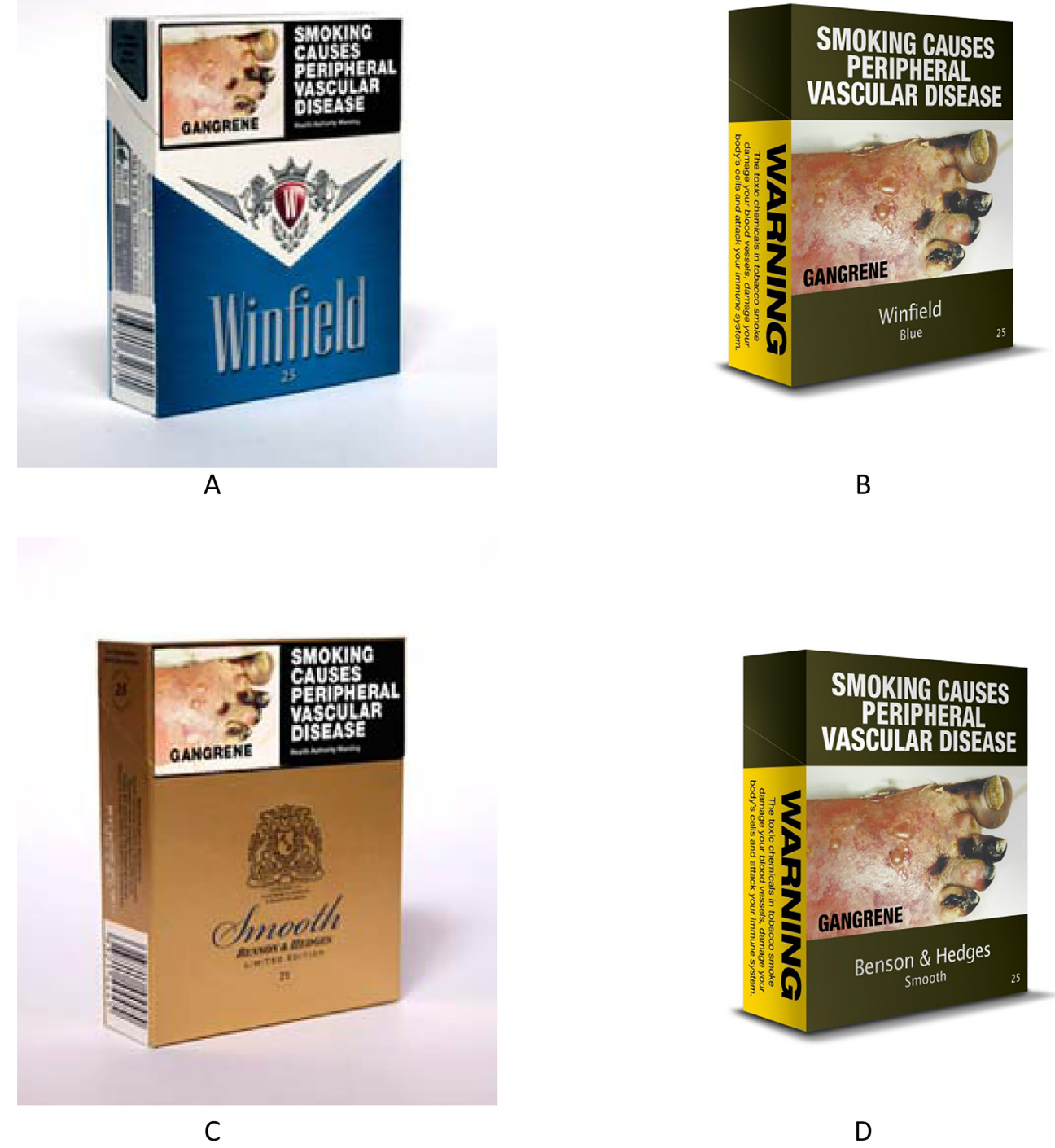

Figure 1 Pack image used for each pack condition within the two by two packaging type (branded vs plain) by brand name (Winfield vs Benson \& Hedges) between-subject experimental design.

One notable finding of this research, demonstrating the importance of branding in the tobacco market, was a possible interaction effect between packaging type (branded vs plain) and brand name (Winfield vs B\&H). Plain pack images were rated consistently lower than branded images on measures of positive pack, positive smoker and positive taste appeal for the Winfield condition, but no differences were detected for the B\&H condition. It might be expected that plain packaging of $\mathrm{B} \& \mathrm{H}$ cigarettes is unlikely to have much effect among socially disadvantaged smokers as this brand is positioned as a premium product at a high price point, ${ }^{29}$ with apparent low penetration among this smoker group: only $1.6 \%$ of participants reported regularly using $\mathrm{B} \& \mathrm{H}$ cigarettes compared with $9 \%$ in the general population. ${ }^{28}$ Comparatively, engagement with the 'mainstream', value-for-money Winfield brand is much higher among socially disadvantaged smokers: participants reported regularly using this brand at the same rate as the general population $(19 \%) .{ }^{28}$ Plain packaging has the potential to show stronger effects for brands that are personally relevant to the individual smoker.

Similarly to Wakefield et als previous simulation studies, this study found no difference between plain and branded cigarette packaging on negative harm ratings. This may indicate that the removal of branding elements such as colours, logos and fonts on packs is more effective in reducing brand appeal associations rather than tapping into negative harm perceptions. It is also likely that the measures used in this study, intended to assess brand appeal, were not adequate to assess negative harm perceptions related to packaging. It may also 
A Positive Pack Characteristic Response Scale

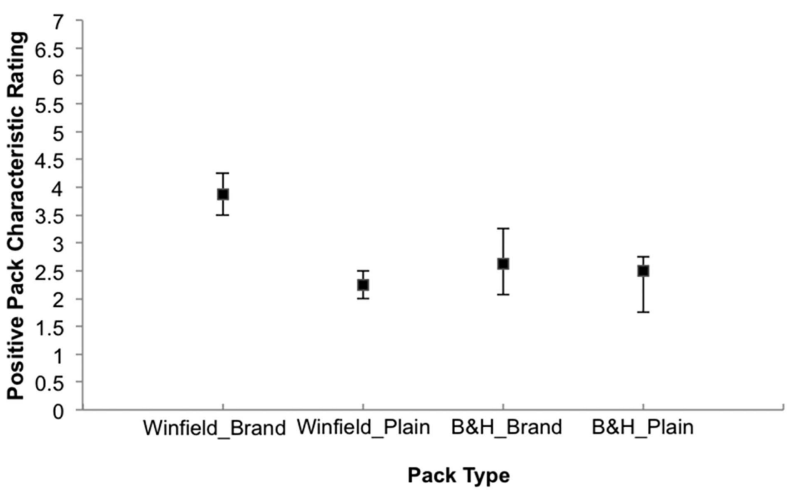

C Negative Smoker Characteristic Response Scale

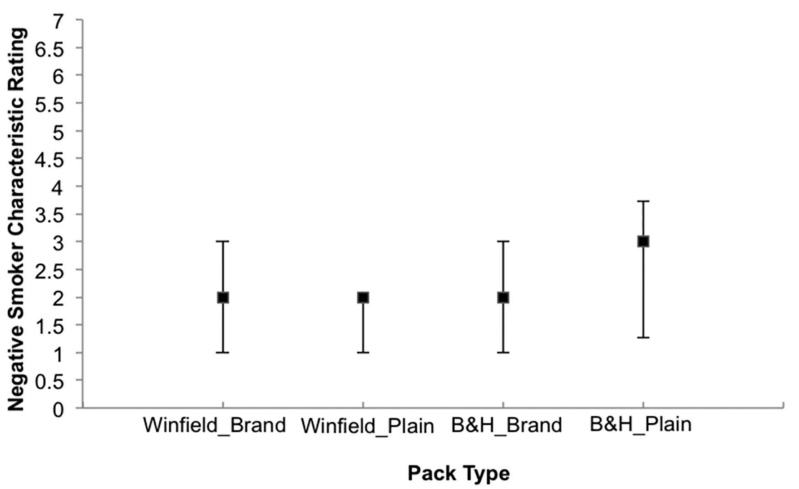

E Negative Harm Characteristic Response Scale

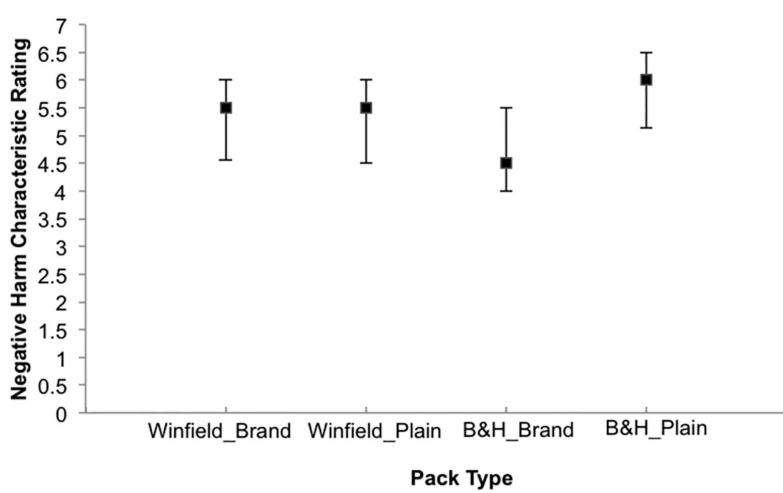

B Positive Smoker Characteristic Response Scale

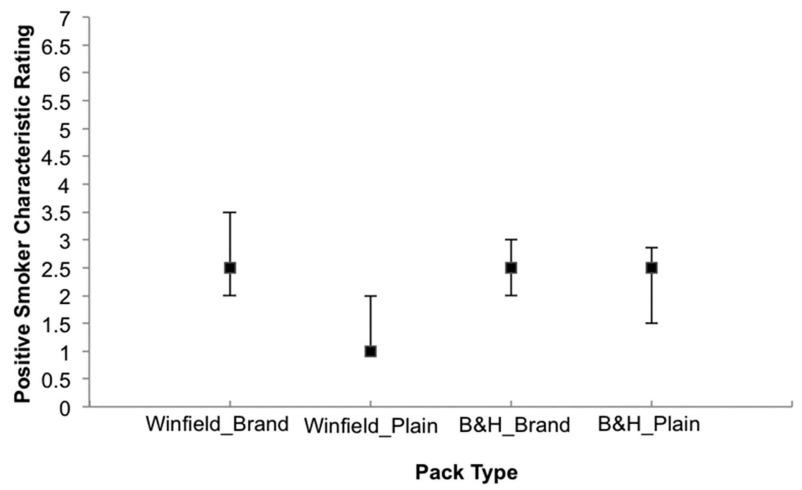

D Positive Taste Characteristic Response Scale

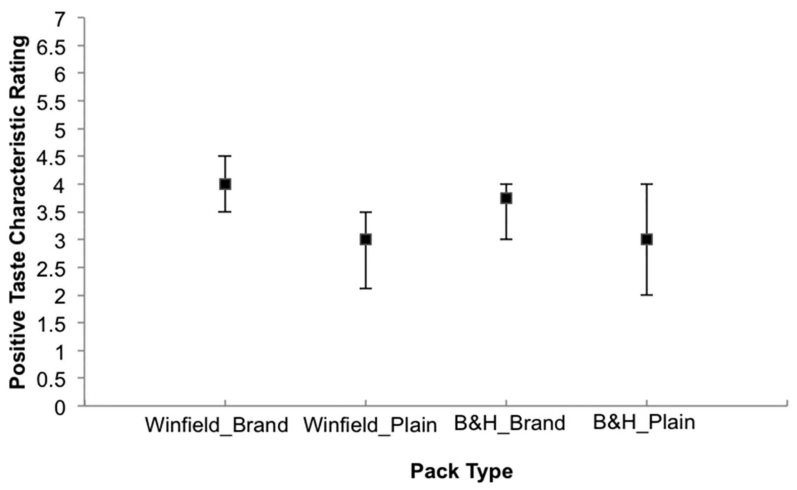

be the case that effects on perceived harm are stronger among youth than among adults, as previous simulation studies indicate plain packaging reduces false beliefs about smoking among adolescents ${ }^{14}$ and increases cessation intentions among young adults. ${ }^{8}$ Our study also found that the presentation of plain packaging, compared with branded packaging, reduced purchase intentions among socioeconomically disadvantaged smokers, consistent with previous simulations conducted with general population smokers. ${ }^{2022}$

\section{Implications}

The results of this study support the move towards plain packaging policies for cigarettes. Most research used in the development of plain packaging policies was conducted with general population samples, with limited data to indicate how socioeconomically disadvantaged groups, who have among the highest smoking rates, may respond to this tobacco control policy. The current study indicates that socioeconomically disadvantaged smokers are likely to respond similarly to the general population, with plain packaging reducing brand appeal ratings and purchase intentions among these smokers. Further research, particularly in low-income countries, could provide insight about the possibility of disseminating this policy internationally.

Early research in Australia indicates plain packaging makes tobacco less appealing and increases the urgency 


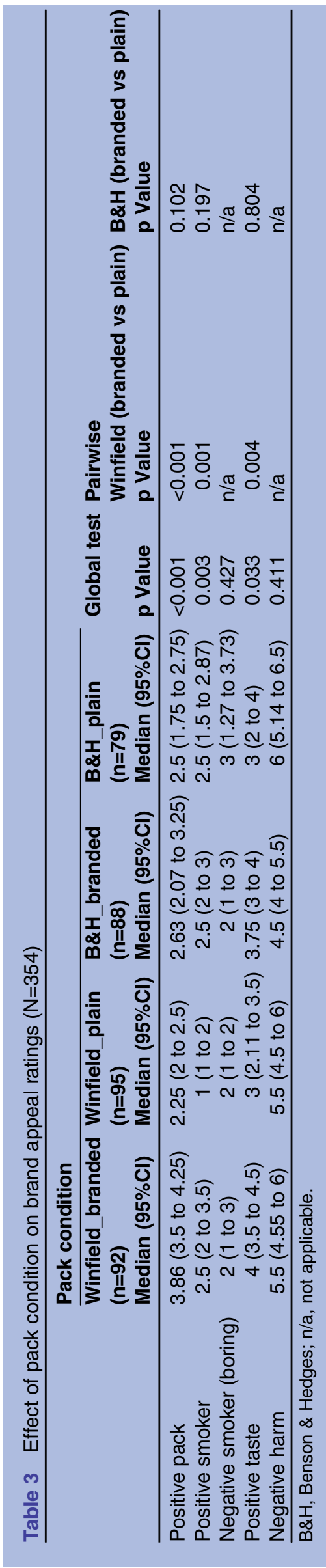

to quit smoking ${ }^{24}$; however, it will be important to monitor impact over time. Plain packaging policies have the potential to reduce smoking initiation. Associations with brand identity and appeal are motivating factors in smoking uptake among youth. ${ }^{30} 31$ There are documented cases of cigarette rebranding, for example, the development of the Camel 'smooth character', to appeal to young adult smokers with the explicit intentions of increasing market share and prevalence of smoking among youth. ${ }^{32}$ Plain packaging policies prevent this kind of brand targeting and have the potential to reduce uptake among youth by reducing brand appeal and purchase intentions. It will also be important to assess the use of any avoidance strategies, such as pack stickers and cigarette cases and to monitor whether these are temporary solutions, or whether ongoing changes to policy are required.

\section{Strengths and limitations}

The primary limitation of the study is its reliance on a convenience sample limiting its external validity and generalisability. However, socially disadvantaged groups are notoriously difficult to recruit and retain in health research. ${ }^{33}{ }^{34}$ Recruitment challenges were overcome by accessing community services as recruitment sites and using convenience samples. As a result, this study is the first to obtain a large sample of socially disadvantaged smokers' responses to a simulation of a one-off exposure to an important tobacco control policy development. Since the policy has been implemented, socially disadvantaged smokers' day-to-day experience is one of being exposed to these plain packs multiple times a day, and so the findings from this study may underestimate the real-world effects of this change. This study was also limited by the measurement of purchase intentions rather than actual behaviour, the use of only two cigarette brands for comparison. Use of a wider range of brands for comparison is recommended for research in countries considering implementing plain packaging. Although the study employed a computer image instead of actual packs, previous packaging research demonstrates that results are generally consistent regardless of stimulus presentation modality. ${ }^{22} 3536$ The outcome measures used in this study pose an additional limitation. Although they were selected for the purpose of comparing results with previous plain pack research, ${ }^{19} 20$ they have not been evaluated for validity or reliability and this should be assessed in the future.

As this study tested the Australian Government's new plain pack design, which combines plain packaging with larger HWLs, we were unable to distinguish which factor (plain packaging or larger HWLs) produced the observed results. Previously, Wakefield et $a l^{20}$ examined the importance of branding versus HWL size on cigarette packaging, concluding that plain packaging reduced elements of brand appeal far more than increasing the size of HWLs. In their study, when packs were plain, increasing the size of HWLs above $30 \%$ did 
not reduce brand appeal further. This finding suggests that the effects observed in the current study are more likely due to stripping the pack of branding elements, than increasing the HWL size. Finally, the last 23 months of survey occurred during the policy roll-out phase and participants may have already been exposed to and purchased plain packs. Prior exposure may have allowed participants to become familiar with the new pack designs, and may explain why participants did not rate packs differently on negative harm and smoker measures.

\section{CONCLUSIONS}

The findings of this study support plain packaging policy, and show this strategy has the potential to reduce positive associations with cigarette packs among a group of highly socioeconomically disadvantaged smokers. It will be important to monitor the long-term outcomes of plain packaging policy, particularly with regard to uptake of smoking in disadvantaged groups. Further plain pack research in low-income countries is recommended, to support the potential dissemination of the policy internationally.

\section{Author affiliations}

${ }^{1}$ School of Medicine \& Public Health, University of Newcastle, Newcastle, New South Wales, Australia

${ }^{2}$ Health Behaviour Research Group, School of Medicine \& Public Health, University of Newcastle \& Hunter Medical Research Institute, Newcastle, New South Wales, Australia

${ }^{3}$ Centre for Behavioural Research in Cancer, The Cancer Council Victoria, Melbourne, Victoria, Australia

${ }^{4}$ Centre for Clinical Epidemiology and Biostatistics, School of Medicine \& Public Health, University of Newcastle \& Hunter Medical Research Institute, Newcastle, New South Wales, Australia

Acknowledgements The authors thank the Social and Community Service Organisation and its clients involved in this research, as well as Melinda Hickey, Jessica Masey and Jodie Schroder for their roles in recruiting clients into the project.

Contributors AG led data collection, analysis and manuscript write-up. BB, $\mathrm{CP}$ and CDE oversaw data collection. CDE and SD advised on and CDE oversaw data analysis. All authors contributed to the concept development and design of the project, manuscript drafts and approved of the final manuscript.

Funding This study was part of a project funded by a grant from the Hunter Medical Research Institute (G1101150).

Competing interests AG was supported by an Australian Postgraduate Award PhD scholarship administered through the University of Newcastle. BB was supported by a Cancer Institute NSW Career Development Fellowship. CP was supported by Cancer Control Collaboration funding.

Ethics approval University of Newcastle's Human Research Ethics Committee.

Provenance and peer review Not commissioned; externally peer reviewed.

Data sharing statement No additional data are available.

Open Access This is an Open Access article distributed in accordance with the Creative Commons Attribution Non Commercial (CC BY-NC 3.0) license, which permits others to distribute, remix, adapt, build upon this work noncommercially, and license their derivative works on different terms, provided the original work is properly cited and the use is non-commercial. See: http:// creativecommons.org/licenses/by-nc/3.0/

\section{REFERENCES}

1. Australian Institute of Health and Welfare. 2010 National Drug Strategy Household Survey Report. Canberra, AlHW2011 Contract No.: Cat. no. PHE 145.

2. Australian Bureau of Statistics, Australian Institute of Health and Welfare. The Health and Welfare of Australia's Aboriginal and Torres Strait Islander Peoples. Commonwealth of Australia: Canberra, 2008.

3. Connor SE, Cook RL, Herbert MI, et al. Smoking cessation in a homeless population: there is a will, but is there a way? J Gen Intern Med 2002;17:369-72.

4. Kermode $\mathrm{M}$, Crofts $\mathrm{N}$, Miller $\mathrm{P}$, et al. Health indicators and risks among people experiencing homelessness in Melbourne, 19951996. Aust N Z J Public Health 1998;22:464-70.

5. Lasser K, Boyd JW, Woolhandler S, et al. Smoking and mental illness: a population-based prevalence study. JAMA 2000;284:2606-10.

6. Moeller-Saxone K. Cigarette smoking and interest in quitting among consumers at a Psychiatric Disability Rehabilitation and Support Service in Victoria. Aust N Z J Public Health 2008;32:479-81.

7. Reichler $\mathrm{H}$, Baker $\mathrm{A}$, Lewin $\mathrm{T}$, et al. Smoking among in-patients with drug-related problems in an Australian psychiatric hospital. Drug Alcohol Rev 2001;20:231-7.

8. Hoek J, Wong C, Gendall P, et al. Effects of dissuasive packaging on young adult smokers. Tob Control 2011;20:183-8.

9. Wakefield M, Morley C, Horan JK, et al. The cigarette pack as image: new evidence from tobacco industry documents. Tob Control 2002; $11: 173-80$.

10. Ford A, Moodie C, Hastings $G$. The role of packaging for consumer products: understanding the move towards 'plain' tobacco packaging. Addict Res Theory 2012;20:339-47.

11. Carpenter CM, Wayne GF, Connolly GN. Designing cigarettes for women: new findings from the tobacco industry documents. Addiction 2005:100:837-51.

12. Cummings KM, Morley CP, Horan JK, et al. Marketing to America's youth: evidence from corporate documents. Tob Control 2002;11:i5-17.

13. Anderson S, Hastings G, MacFadyen L. Strategic marketing in the UK tobacco industry. Lancet Oncol 2002;3:481-6.

14. Hammond D, Dockrell M, Arnott D, et al. Cigarette pack design and perceptions of risk among UK adults and youth. Eur J Public Health 2009;19:631-7.

15. Bansal-Travers M, O'Connor R, Fix BV, et al. What do cigarette pack colors communicate to smokers in the U.S.? Am J Prev Med 2011;40:683-9.

16. Hammond D. FCTC Article 11: Tobacco labelling and packaging: a review of evidence. 2007. http://www.cctc.ca/cctc/EN/tcrc/books/ tcmonograph.2007-12-19.7863543963\#.UKsFEldkyAg

17. Bansal-Travers $M$, Hammond $D$, Smith $P$, et al. The impact of cigarette pack design, descriptors, and warning labels on risk perception in the US. Am J Prev Med 2011;40:647-82.

18. Hammond D. Health warning messages on tobacco products: a review. Tob Control 2011;20:327-37.

19. Wakefield MA, Germain D, Durkin SJ. How does increasingly plainer cigarette packaging influence adults smokers' perceptions about brand image? An experimental study. Tob Control 2008;17:416-21.

20. Wakefield M, Germain D, Durkin S, et al. Do larger pictorial health warnings diminish the need for plain packaging of cigarettes? Addiction 2012;107:1159-67.

21. Germain D, Wakefield MA, Durkin SJ. Adolescents' perceptions of cigarette brand image: Does plain packaging make a difference? $J$ Adolesc Health 2010;46:385-92.

22. Thrasher JF, Rousu MC, Hammond D, et al. Estimating the impact of pictorial health warnings and "plain" cigarette packaging: evidence from experimental auctions among adult smokers in the United States. Health Policy 2011;102:41-8.

23. Department of Health and Ageing. Tobacco plain packaging bill 2011. Canberra: Department of Health and Ageing, 2011.

24. Wakefield MA, Hayes L, Durkin S, et al. Introduction effects of the Australian plain packaging policy on adult smokers: a cross-sectional study. BMJ Open 2013;3:e003175.

25. Australian Council of Social Service. Australian community sector survey report 2011 volume 1-National. Strawberry Hills: Australian Council of Social Service, 2011.

26. Bryant J, Bonevski B, Paul C. A survey of smoking prevalence and interest in quitting among social and community service organisation 
clients in Australia: a unique opportunity for reaching the disadvantaged. BMC Public Health 2011;11:827.

27. Creseo Corporation. Digivey survey suite. Arizona.

28. Scollo MM, Winstanley MH. Tobacco in Australia: Facts and issues. 4th edn. Melbourne: Cancer Council Victoria, 2012 (cited Aug 2013) http://www.TobaccolnAustralia.org.au

29. Carter SM. The Australian cigarette brand as product, person, and symbol. Tob Control 2003;12:iii79-86.

30. DiFranza JR, Wellman RJ, Sargent JD, et al. Tobacco promotion and the initiation of tobacco use: assessing the evidence for causality. Pediatrics 2006;117:e1237-e48.

31. Gendall P, Hoek J, Thomas JL, et al. Young adults' interpretation of tobacco brands: implications for tobacco control. Nicotine Tob Res 2011:13:911-18.

32. Wayne GF, Connolly GN. How cigarette design can affect youth initiation into smoking: camel cigarettes 1983-93. Tob Control 2002;11:i32-i39.
33. UyBico SJ, Pavel S, Gross CP. Recruiting vulnerable populations into research: a systematic review of recruitment interventions. J Gen Intern Med 2007;22:852-63.

34. Yancey AK, Ortega AN, Kumanyika SK. Effective recruitment and retention of minority research participants. Annu Rev Public Health 2006;27:1-28.

35. Hammond D, Thrasher J, Reid JL, et al. Perceived effectiveness of pictorial health warnings among Mexican youth and adults: a population-level intervention with potential to reduce tobacco-related inequities. Cancer Causes Control 2012;23 (Suppl 1):57-67.

36. Thrasher JF, Arillo-Santillan E, Villalobos V, et al. Can pictorial warning labels on cigarette packages address smoking-related health disparities? Field experiments in Mexico to assess pictorial warning label content. Cancer Causes Control 2012;23 (Suppl 1):69-80. 